\title{
The role of $\mathrm{ZBTB38}$ in promoting migration and invasive growth of bladder cancer cells
}

\author{
JINGCHEN JING ${ }^{1,2}$, JIE LIU ${ }^{1,2}$, YAOCHUN WANG ${ }^{1,2}$, MIAO ZHANG $^{1,2}$, \\ LU YANG ${ }^{1,2}$, FEIYU SHI ${ }^{3}$, PEIJUN LIU ${ }^{1,2^{*}}$ and JUNJUN SHE ${ }^{3 *}$ \\ ${ }^{1}$ Center for Translational Medicine, The First Affiliated Hospital, Xi'an Jiaotong University; \\ ${ }^{2}$ Key Laboratory for Tumor Precision Medicine of Shaanxi Province, The First Affiliated Hospital, Xi'an Jiaotong University; \\ ${ }^{3}$ Department of General Surgery, The First Affiliated Hospital, Xi'an Jiaotong University, Xi'an, Shaanxi 710061, P.R. China
}

Received June 28, 2018; Accepted December 6, 2018

DOI: $10.3892 /$ or.2018.6937

\begin{abstract}
Bladder cancer is the most common malignancy of the urinary tract, and $\sim 50 \%$ of patients with bladder cancer experience recurrence and metastasis. The results of mass spectrometry revealed that the expression of zinc finger and BTB domain-containing 38 (ZBTB38) was higher in highly aggressive human bladder cancer $253 \mathrm{~J}$ B-V cells compared with in the less aggressive bladder cancer 253J cells. However, the association between ZBTB38 and bladder cancer is currently not well defined, and the association of ZBTB38 with migration and invasive growth of bladder cancer cells remains unclear. Previous studies have suggested that ZBTB38 may act as an oncogene, similar to Kaiso. Furthermore, analysis of a clinical database suggested that ZBTB38 expression may be associated with poor prognosis of patients with bladder cancer. Using cell proliferation, migration and invasion assays, and western blotting, the present study demonstrated that ZBTB38 promoted the migration and invasive growth of bladder cancer cells, but inhibited their proliferation. Further experiments suggested that ZBTB38 promoted epithelial-mesenchymal transition and the expression levels of genes downstream of the Wnt/ $\beta$-catenin signaling pathway. Notably, further experiments using a xenograft tumor metastasis model revealed that ZBTB38 promoted bladder cancer lung metastasis in vivo. These findings suggested that ZBTB38 promoted migration
\end{abstract}

Correspondence to: Dr Peijun Liu, Center for Translational Medicine, The First Affiliated Hospital, Xi'an Jiaotong University, 277 Yanta West Road, Xi'an, Shaanxi 710061, P.R. China

E-mail: liupeijun@mail.xjtu.edu.cn

Dr Junjun She, Department of General Surgery, The First Affiliated Hospital, Xi'an Jiaotong University, 277 Yanta West Road, Xi'an, Shaanxi 710061, P.R. China

E-mail: sjuns@sina.com

${ }^{*}$ Contributed equally

Key words: ZBTB38, bladder cancer, migration, invasion, $\mathrm{Wnt} / \beta$-catenin signaling pathway and invasive growth of bladder cancer cells through facilitation of the Wnt/ $\beta$-catenin signaling pathway. To the best of our knowledge, this is the first study to reveal that ZBTB38 may promote migration and invasive growth of bladder cancer cells via modulation of the $\mathrm{Wnt} / \beta$-catenin signaling pathway.

\section{Introduction}

Bladder cancer is the most common malignancy of the urinary tract and is associated with a high rate of tumor recurrence. At present, an estimated 79,000 new cases of bladder cancer and 16,800 cases of bladder cancer-associated mortality are recorded each year in the US (1). Despite advances in bladder cancer therapies, $\sim 50 \%$ of patients develop metastasis (2); therefore, it is important to investigate the mechanisms underlying metastasis of bladder cancer cells.

Molecular studies on bladder cancer have largely focused on mutations in fibroblast growth factor receptor 3 , tumor protein p53 $(3,4)$ and other genes $(5,6)$. Furthermore, deletion of chromosome 9 is detected in the majority of cases of non-muscle invasive bladder cancer (7). In addition, factors associated with bladder cancer include the phosphatidylinositol-3-kinase/protein kinase B/mechanistic target of rapamycin pathway, RAS, cell cycle progression and receptor tyrosine kinases (8-10). Two bladder cancer cell lines, 253J $\mathrm{B}-\mathrm{V}$ and 253J, were used in the present study. The 253J B-V cell line is derived from $253 \mathrm{~J}$, and exhibits a propensity for tumor formation and metastasis. Using a protein chip, we revealed that the protein expression levels of zinc finger and BTB domain-containing 38 (ZBTB38) were higher in 253J $\mathrm{B}-\mathrm{V}$ cells compared with in $253 \mathrm{~J}$ cells (She et al, unpublished data). However, the role of ZBTB38 in bladder cancer is not well characterized; therefore, it is important to investigate whether ZBTB38 can promote the migration and invasive growth of bladder cancer cells.

ZBTB38 contains $10 \mathrm{C}_{2} \mathrm{H}_{2}$-type zinc fingers domains and an N-terminal BTB/POZ domain, namely Kaiso-like protein $(11,12)$. Few studies have investigated the functional role of ZBTB38 in cancer. For example, ZBTB38 has been reported to recognize and bind to genes harboring $\mathrm{CpG}$ islands, particularly the promoters of tumor suppressors $(11,13-15)$. In addition, Kaiso is associated with metastasis in the context 
of several types of cancer $(16,17)$ and has a close connection with the Wnt signaling pathway (18-20). The Wnt/ $\beta$-catenin signaling pathway, also known as the canonical Wnt pathway, is closely associated with malignant transformation of cancer cells and metastasis $(21,22)$. In addition, the $\mathrm{Wnt} / \beta$-catenin pathway has been demonstrated to be involved in the development of bladder cancer (23).

The present study aimed to investigate whether ZBTB38 can promote the migration and invasive growth of bladder cancer cells, and to identify the possible effects of ZBTB38 on the Wnt/ $\beta$-catenin signaling pathway. To the best of our knowledge, this is the first study to investigate the role of ZBTB38 in bladder cancer.

\section{Materials and methods}

Cell culture. The SV-HUC-1 human normal bladder cell line, and the 253J, 253J B-V, 5637, T24 and J82 bladder cancer cell lines were obtained from Professor Junjun She (The First Affiliated Hospital of Xi'an Jiaotong University, Xi'an, China). $253 \mathrm{~J}$ B-V cells were developed from $253 \mathrm{~J}$ cells. Briefly, the $253 \mathrm{~J}$ cells were injected into the bladder of nude mice. After 6 months, a tumor appeared in the bladder. The tumor was cultured and named 253J B-I, which was again injected into the bladder of nude mice. By repeating this process 4 times, the 253J B-V cells were obtained; these cells possess a stronger ability for metastasis (24). All cells were cultured in Dulbecco's modified Eagle's medium (DMEM; Gibco; Thermo Fisher Scientific, Inc., Waltham, MA, USA) supplemented with $10 \%$ fetal bovine serum (FBS; HyClone; GE Healthcare Life Sciences, Logan, UT, USA). The cells were cultured in $100-\mathrm{mm}$ dishes at $37^{\circ} \mathrm{C}$ in an atmosphere containing $5 \% \mathrm{CO}_{2}$ and saturated humidity.

Cell transfection and RNA interference. Small interfering siRNAs were synthesized by Shanghai GenePharma Co., Ltd., (Shanghai, China), and the plasmid was synthesized by Shanghai GeneChem Co., Ltd. (Shanghai, China). Plasmid and siRNA transfection was performed using Lipofectamine ${ }^{\circledR} 2000$ (Invitrogen; Thermo Fisher Scientific, Inc.). Briefly, 253J cells were transfected with plasmids ( $4 \mu \mathrm{g}$; $2 \mathrm{ng} / \mu \mathrm{l}$ ) once they reached $80-90 \%$ cell confluence in a 6 -well plate, whereas $253 \mathrm{~J}$ B-V cells were transfected with siRNAs (50 $\mathrm{nM}$ ) once they reached $70-80 \%$ cell confluence in a 6 -well plate; $\sim 6 \mathrm{~h}$ post-transfection, the supernatants were replaced with fresh medium. After $48 \mathrm{~h}$, the cells were harvested for experiments. The siRNA sequences used in the present study were as follows: ZBTB38-1, 5'-CACUAUCAUUGUGGA AGAUTT-3'; ZBTB38-2, 5'-CCUAGUGUCUAUCCGUAU ATT-3'; control (non-targeting), 5'-UUCUCCGAACGUGUC ACGUTT-3'. The plasmids were constructed by cloning the ZBTB38 siRNA sequences into GV141 vectors (Shanghai GeneChem Co., Ltd.), which contained the following information: CMV-MCS-3FLAG-SV40-Neomycin; the restriction site was $X h o I / K p n I$ and the plasmid was ampicillin-resistant. The negative control was an empty vector (pcDNA3.1-3FLAG; Shanghai GeneChem Co., Ltd.).

RNA extraction and reverse transcription-quantitative polymerase chain reaction $(R T-q P C R)$. Total RNA was extracted from cells using RNA fast200 (Fastagen, Shanghai, China). The 5X PrimeScript RT Master Mix (Takara Biotechnology Co., Ltd., Dalian, China) was used to reverse transcribe mRNA into cDNA, according to the manufacturer's protocol. qPCR was performed using 2X SYBR-Green Mix (Takara Biotechnology Co., Ltd.) and a Bio-Rad detection system (Bio-Rad Laboratories, Inc., Hercules, CA, USA). The reactions were visualized according to the manufacturer's protocol, as follows: $95^{\circ} \mathrm{C}$ for $30 \mathrm{sec}$, followed by 40 cycles at $95^{\circ} \mathrm{C}$ for $5 \mathrm{sec}$ and $60^{\circ} \mathrm{C}$ for $30 \mathrm{sec}$, and then one cycle at $65^{\circ} \mathrm{C}$ for $5 \mathrm{sec}$ and $95^{\circ} \mathrm{C}$ for $50 \mathrm{sec}$, and were quantified using the $2^{-\Delta \Delta \mathrm{Cq}}$ method (25). The primers used were as follows: ZBTB38, forward 5'-TGTCTTGAAGTGAGGCTCTGCTG-3', reverse 5'-AGCAAGCCTTGTGGACCAAAC-3'; E-cadherin, forward 5'-gAgTgCCAACTggACCATTCAgTA-3', reverse 5'-AgTCACCCACCTCTAAggCCATC-3'; vimentin, forward 5'-TgACATTgAgATTgCCACCTACAg-3', and reverse 5'-TCA ACCGtcTTAATCAgAAgTgTCC-3'; and GAPDH, forward 5'-agaaggctggggctcatttg-3' and reverse 5'-aggggccatccacagtct tc-3'. GAPDH was used as an internal control.

Patients and tissue specimens. The present study was conducted in accordance with the Code of Ethics of the World Medical Association. A total of 6 pairs of bladder cancer tissues (each pair consisted of one tumor sample and one paracarcinoma sample) were obtained from 6 patients, and two normal bladder tissues were also obtained from two of the 6 patients. All of the tissues were obtained from the Pathology Department of the First Affiliated Hospital of Xi'an Jiaotong University; the present study was approved by the Ethical Committee on Human Research of the First Affiliated Hospital of Xi'an Jiaotong University. Patients provided written informed consent for the use of their tissues. Images of the tissues were captured using a Leica SCN400 slide scanner (Leica Microsystems, Inc., Buffalo, Grove, IL, USA).

Western blotting. Proteins were extracted from cells for western blotting using radioimmunoprecipitation assay lysis buffer [0.05 M Tris- $\mathrm{HCl}$ (pH 7.4), $0.15 \mathrm{mM} \mathrm{NaCl}, 1 \%$ Triton $\mathrm{X}-100,0.1 \%$ SDS, $0.001 \mathrm{M}$ EDTA, 1\% sodium deoxycholate and protease inhibitors]. Protein concentration was then quantified using the bicinchoninic acid method. Subsequently, proteins $(50 \mu \mathrm{g}, 3 \mu \mathrm{g} / \mu \mathrm{l})$ were separated by $10 \%$ SDS-PAGE and transferred to polyvinylidene fluoride membranes (0.22 $\mu \mathrm{m}$; EMD Millipore, Billerica, MA, USA). The membranes were blocked with $5 \%$ skimmed milk containing Tris-buffered saline and 0.1\% Tween-20 (TBST) for $2 \mathrm{~h}$ at $37^{\circ} \mathrm{C}$, and were probed with respective antibodies at $4^{\circ} \mathrm{C}$ overnight. After washing with TBST $(0.1 \%)$, the membranes were incubated with anti-mouse or anti-rabbit secondary antibodies. Immunoblots were detected using the Bio-Rad ChemiDoc $^{\mathrm{TM}}$ XRS+ system (Bio-Rad Laboratories, Inc.) through enhanced chemiluminescence (Immobilon western HRP substrate; Merck KGaA, Darmstadt, Germany). The blots were semi-quantified by Image Lab software, version 3.0 (Bio-Rad Laboratories, Inc.)

Antibodies. ZBTB38 (1:100, cat. no. ab50664; Abcam, Cambridge, MA, USA) was used for immunohistochemistry (IHC). The following primary antibodies were used 
for western blotting: ZBTB38 (1:500, cat. no. ab112051; Abcam), E-cadherin (1:1,000, cat. no. 14472: Cell Signaling Technology, Inc., Danvers, MA, USA); zonula occludens (ZO)-1 (1:1,000, cat. no. 13663; Cell Signaling Technology, Inc.); vimentin $(1: 1,000$, cat. no. 5741; Cell Signaling Technology, Inc.); $\beta$-catenin $(1: 1,000$, cat. no. 8480; Cell Signaling Technology, Inc.); Wnt/ $\beta$-catenin activated targets antibody sampler kit $(1: 1,000$, cat. no. 8655 ; Cell Signaling Technology, Inc.); GAPDH (1:10,000, cat. no. HRP-60004; ProteinTech Group, Inc., Chicago, IL, USA); and $\beta$-actin (1:10,000, cat. no. HRP-60008; ProteinTech Group, Inc.). Anti-rabbit and anti-mouse horseradish peroxidase-conjugated secondary antibodies (1:5,000; cat. nos. sc-2004 and sc-2005) were purchased from Santa Cruz Biotechnology, Inc. (Dallas, TX, USA).

Cell proliferation. The MTT assay (Amresco, LLC, Solon, $\mathrm{OH}, \mathrm{USA}$ ) was used to assess cell proliferation. Briefly, 253J and 253J B-V cells were transfected with plasmid or siRNAs. After $24 \mathrm{~h}$, cells were transferred from 6-well plates to 48-well plates ( $\sim 30 \%$ cell confluence). Subsequently, $50 \mu 1$ MTT was added to each well for $4 \mathrm{~h}$ at $37^{\circ} \mathrm{C}$, after which, $375 \mu$ ldimethyl sulfoxide was added. Subsequently, cells were measured at an optical density of $490 \mathrm{~nm}$ every day for 3 successive days.

Wound-healing and Transwell assays. Prior to the woundhealing assay, 253J and 253J-B-V cells were transfected with plasmid or siRNAs in 6-well plates, respectively. The cells (90-100\% confluence) were starved of serum for $12 \mathrm{~h}$ prior to experimentation and pipette tips were used to generate wounds in the cell layer; subsequently, the cells were washed with PBS and placed in fresh medium. Microscopic images of the wound were obtained at 0,8 and $24 \mathrm{~h}$ (magnification, $\mathrm{x} 10$; Leica DMi8; Leica Microsystems, Inc.). For the Transwell assay, a total of $24 \mathrm{~h}$ post-transfection, $2 \times 10^{4}$ cells were placed in 24-well Transwell chambers with polycarbonate filters (pore size, $8 \mu \mathrm{m}$; Corning Incorporated, Corning, NY, USA). For the invasion assay, $2 \times 10^{5}$ cells suspended in medium without FBS were seeded in the upper chambers, which were coated with Matrigel (1:10; BD Biosciences, Franklin Lakes, NJ, USA). For the migration assay, $2 \times 10^{4}$ cells were seeded in the upper chambers, which were uncoated. The insert was incubated in $600 \mu 1$ DMEM supplemented with $10 \% \mathrm{FBS}$ at $37^{\circ} \mathrm{C}$ in an atmosphere containing $5 \% \mathrm{CO}_{2}$. Subsequently, the cells were fixed in $95 \%$ ethanol at $25^{\circ} \mathrm{C}$ for $20 \mathrm{~min}$, stained with $0.3 \%$ crystal violet at $25^{\circ} \mathrm{C}$ for $15 \mathrm{~min}$ and scrubbed gently to remove the non-migratory and non-invasive cells. Images were captured under a microscope (magnification, x20; Leica DMi8; Leica Microsystems, Inc.).

Bladder cancer survival analysis. Gepia survival analysis for clinical outcomes [disease-free survival (DFS)] of patients with bladder cancer was performed using web tool survival plots (http://gepia.cancer-pku.cn/). The data (402 samples) used by Gepia were obtained from The Cancer Genome Atlas database. The percentiles of patients were auto selected based on the best performing thresholds.

Xenograft model of bladder cancer lung metastasis. All animal procedures complied with the Guidelines of the
Institutional Animal Use and Care Committee of Xi'an Jiaotong University. The animal procedures were approved by the Institutional Animal Use and Care Committee of Xi'an Jiaotong University (no. XJTULAC2018-505). A total of 104 -week-old SCID male mice ( $\mathrm{n}=5$ mice/group) were purchased from the Centre of Laboratory Animals (The Medical College of Xi'an Jiaotong University) and were maintained according to the guidelines of the Centre of Laboratory Animals. The mice were maintained as follows: Temperature, $21 \pm 2^{\circ} \mathrm{C}$; humidity, $40-70 \%$; 12-h light/dark cycle; ad libitum access to food and water. All mice were randomly assigned into experimental groups (control group weight, $20.81 \pm 0.45 \mathrm{~g}$; ZBTB38 knock down group weight, $21.10 \pm 0.37 \mathrm{~g}$ ). The siRNA sequence used in this experiment was ZBTB38-2 (5'-CCUAGUGUCUAUCCGUAUATT-3'). Briefly, 253J B-V control cells and ZBTB38 siRNA-transfected 253J B-V cells $\left(1 \times 10^{6}\right.$, diluted in $\left.100 \mu 1 \mathrm{PBS}\right)$ were injected into the lateral tail vein of SCID mice; mice were monitored daily. When the first mice began to suffer from serious tumor burden, at 4 weeks, and the other mice exhibited various levels of emaciation, all animals were sacrificed. Both scientific and humane endpoints were taken into account (26). Notably, the body condition of the mice was observed daily; although there were no significant alterations in body weight, the loss of muscle and subcutaneous fat led to reduced body condition. This could be detected through feeling the pelvis and backbone of the mice. These alterations indicated the possibility of serious tumor burden. A total of 4 weeks after cell injection, all mice were sacrificed, and the lungs were dissected, weighed, photographed and fixed in $4 \%$ paraformaldehyde for $48 \mathrm{~h}$ at $4^{\circ} \mathrm{C}$.

IHC and hematoxylin and eosin $(H \& E)$ staining. Paraffinembedded sections were deparaffinized in xylene and rehydrated in a decreasing concentration gradient of ethanol (100, 95, 80 and $75 \%$ ). After 3 washes (5 min/wash) with PBS, the sections were incubated with $3 \%$ hydrogen peroxide for $10 \mathrm{~min}$ at $37^{\circ} \mathrm{C}$. For antigen retrieval, the sections were placed in sodium citrate $(\mathrm{pH}$ 9.0) in a microwave oven on high heat for $5 \mathrm{~min}$, and on medium heat for $13 \mathrm{~min}$. After cooling to room temperature, sections were washed with $\mathrm{PBS}$ and were incubated with bovine serum albumin (Amresco, LLC) for $30 \mathrm{~min}$ at $37^{\circ} \mathrm{C}$. Subsequently, the sections were incubated overnight with the primary antibody in a moist box at $4^{\circ} \mathrm{C}$. After rinsing with PBS, the sections were incubated with the secondary antibody $(1: 100)$ at $37^{\circ} \mathrm{C}$ for $15 \mathrm{~min}$ included in the kit (cat. no. SP-9001; OriGene Technologies, Inc., Beijing, China), according to the manufacturer's protocol. Finally, DAB (1:1,000; cat. no. ZLI-9017; OriGene Technologies, Inc.) was used to stain sections at $25^{\circ} \mathrm{C}$ for $2 \mathrm{~min}$, followed by counterstaining with hematoxylin (at $25^{\circ} \mathrm{C}$ for $10 \mathrm{~min}$. The sections were then dehydrated in a graded ethanol series $(50,75,95$ and $100 \%)$.

The protocol for H\&E staining was similar to that for IHC. Following immersion of the sections in xylene and ethanol $(100,95,80$ and $75 \%)$, they were counterstained with hematoxylin at $25^{\circ} \mathrm{C}$ for $10 \mathrm{~min}$. Subsequently, the sections were placed in eosin for $2 \mathrm{~min}$ and dehydrated with ethanol. All sections were examined using a microscope slide scanner (Leica MP SCN400; Leica Microsystems, Inc.). 
A

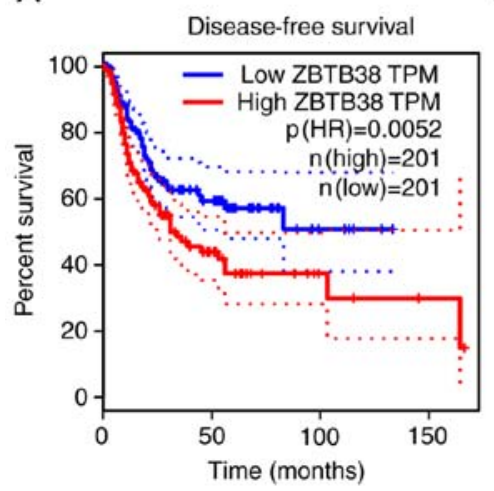

C

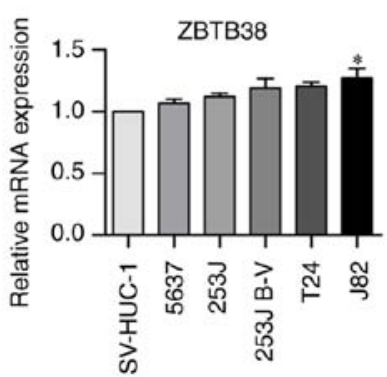

B Normal bladder tissues Less aggressive BLCA Highly aggressive BLCA

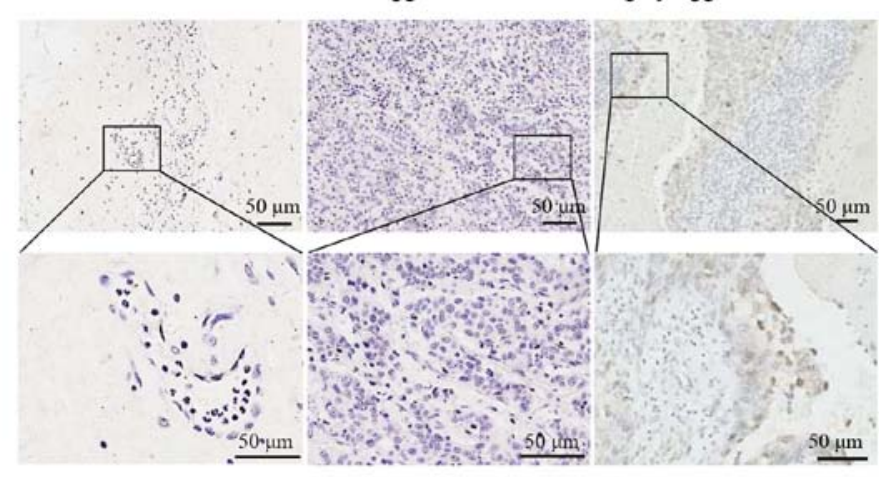

D
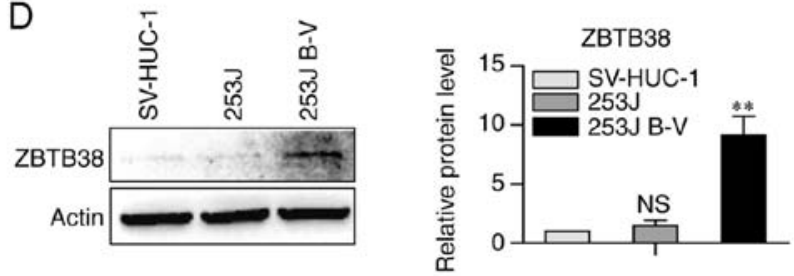

Figure 1.ZBTB38 expression is associated with poor prognosis of patients with bladder cancer. (A) Using The Cancer Genome Atlas database, the association between the mRNA expression levels of ZBTB38 and disease-free survival was determined in patients with bladder cancer. (B) Representative immunohistochemical staining images of ZBTB38 expression in human bladder cancer and non-tumor tissues; scale bar, $50 \mu \mathrm{m}$. (C) mRNA expression levels of ZBTB38 in SV-HUC-1, 5637, 253J, 253J B-V, T24 and J82 cells lines, as evaluated using reverse transcription-quantitative polymerase chain reaction. SV-HUC-1 cells were used as a control. (D) Protein expression levels of ZBTB38 in SV-HUC-1 normal bladder cells, and 253J and 253J B-V bladder cancer cells. SV-HUC-1 cells were used as a control. Data are presented as the means \pm standard error of the mean. ${ }^{*} \mathrm{P}<0.05,{ }^{* *} \mathrm{P}<0.01$ vs. SV-HUC-1 cells. NS, not significant; ZBTB28, zinc finger and BTB domain-containing 38.

Drug treatment. Following transfection for $24 \mathrm{~h}$, the cells (80-90\% confluence) were treated with $20 \mu \mathrm{M}$ SKL2001 (Selleck Chemicals, Houston, TX, USA) for $24 \mathrm{~h}$, or with $20 \mu \mathrm{M}$ XAV939 (Selleck Chemicals) for $24 \mathrm{~h}$. The cells then underwent western blotting.

Statistical analysis. All experiments were repeated at least 3 times and the results are expressed as the means \pm standard error of the mean; conversely, the animal experiments were performed only once. Statistical analysis was performed using GraphPad Prism 5 (GraphPad Software, Inc., La Jolla, CA, USA). Comparisons between two groups were conducted using unpaired Student's t-test. One-way analysis of variance followed by the Student-Newman-Keuls test was used for multiple comparisons. All statistical tests were two-sided. $\mathrm{P}<0.05$ was considered to indicate a statistically significant difference.

\section{Results}

ZBTB38 is associated with poor prognosis of patients with bladder cancer. It has been reported that $~ 50 \%$ of patients with bladder cancer exhibit local or distant recurrence, which is associated with a high rate of mortality (2). The web tool Gepia (http://gepia.cancer-pku.cn) (27) was used to investigate the association between ZBTB38 expression and the survival rate of patients with bladder cancer. ZBTB38 expression exhibited a significantly negative association with DFS (Fig. 1A). This finding indicated that patients with high levels of ZBTB38 expression have a poor prognosis; therefore, ZBTB38 expression may be considered a marker of poor prognosis. The results of mass spectrometry (She et al, unpublished data) revealed that the protein expression levels of ZBTB38 in 253J B-V cells were $\sim 5.8$ times higher than those in $253 \mathrm{~J}$ cells (data not shown). Therefore, the present study aimed to further investigate the role of ZBTB38 in bladder cancer progression and metastasis. Six cases of paired bladder cancer tissue samples were detected using IHC (Fig. 1B). Positive staining of ZBTB38 was frequently detected in highly aggressive bladder cancer; conversely, the expression levels of ZBTB38 were very low in normal bladder tissues and less aggressive bladder cancer. Subsequently, the mRNA expression levels of ZBTB38 were examined in various human bladder cancer cells distinguished by their metastatic ability (Fig. 1C). The results revealed that the mRNA expression levels of ZBTB38 in the highly aggressive bladder cancer cells were slightly higher compared with in the less aggressive bladder cancer cells. Based on the results of mass spectrometry and the results presented in Fig. 1B, 253J and $253 \mathrm{~J} \mathrm{B-V}$ cells were selected for in vitro experiments. As shown in Fig. 1D, the protein expression levels of ZBTB38 did not differ between the SV-HUC-1 normal bladder cells and 253J bladder cancer cells. However, ZBTB38 expression was significantly higher in highly aggressive 253J B-V bladder cancer cells; ZBTB38 expression increased by $~ 5.8$-fold in $253 \mathrm{~J} \mathrm{B-V}$ cells compared with in 253J cells. Therefore, the present study focused on the effects of ZBTB38 on highly aggressive bladder cancer. Although the mRNA expression levels of ZBTB38 in normal and cancer tissues are interesting 
A
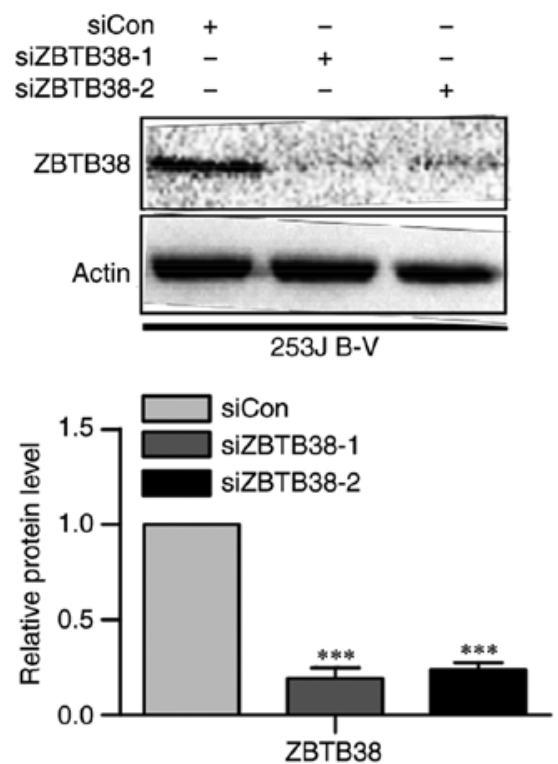

C

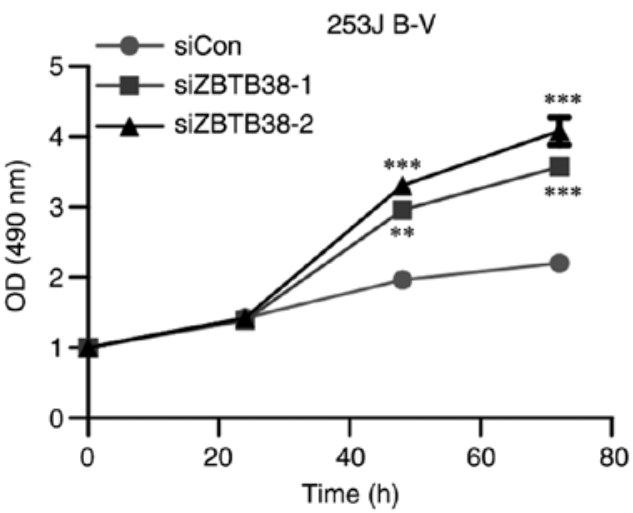

B
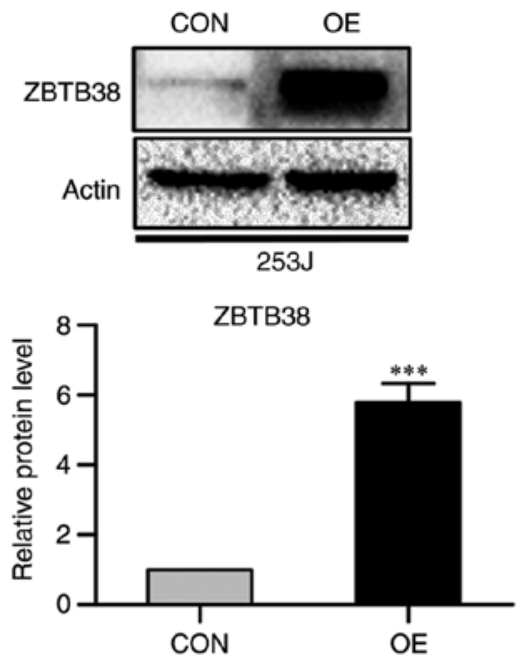

D $253 \mathrm{~J}$

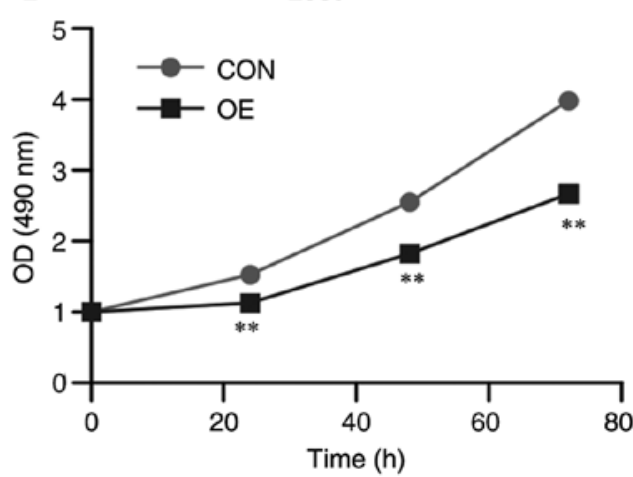

Figure 2.ZBTB38 inhibits the proliferation of bladder cancer cells. (A) Western blotting was used to detect the efficiency of ZBTB38 knockdown. (B) Western blotting was used to detect the efficiency of ZBTB38 OE. Proliferation of (C) 253J B-V and (D) 253J cells was evaluated using the MTT assay. siCon and CON were used as controls. Data are presented as the means \pm standard error of the mean. ${ }^{* *} \mathrm{P}<0.01,{ }^{* * * *} \mathrm{P}<0.001 \mathrm{vs}$. siCon or CON cells. Con/CON, control; OD, optical density; OE, overexpression; si/siRNA, small interfering RNA; ZBTB28, zinc finger and BTB domain-containing 38.

and require further investigation, the present study considered the results of DFS and protein expression analysis sufficient enough to reflect the significant increase of ZBTB38 expression in highly aggressive bladder cancer.

ZBTB38 inhibits cell proliferation, and promotes migration and invasion of bladder cancer cells. Using siRNA, ZBTB38 was knocked down in 253J B-V cells (Fig. 2A). In addition, 253J cells were transfected with a plasmid, in order to induce overexpression of ZBTB38 (Fig. B). After knocking down ZBTB38 in $253 \mathrm{~J} \mathrm{B-V}$ cells, cell proliferation was promoted (Fig. 2C); conversely, the opposite results were obtained following overexpression of ZBTB38 in 253J cells (Fig. 2D). These results indicated that ZBTB38 may inhibit proliferation of bladder cancer cells.

In view of the different expression patterns of ZBTB38 in $253 \mathrm{~J}$ and $253 \mathrm{~J} \mathrm{B-V}$ cells, the present study assessed whether ZBTB38 may induce cancer progression and enhances metastasis of bladder cancer cells. Transwell assay was performed to assess the migratory ability of $253 \mathrm{~J}$ and $253 \mathrm{~J} \mathrm{B-V}$ cells. The results revealed that ZBTB38 knockdown reduced the migratory ability of highly aggressive bladder cancer cells, whereas migration was increased in the less aggressive bladder cancer cells overexpressing ZBTB38 (Fig. 3A and B). The results of the wound-healing (Fig. 3C and D) and Transwell assays (Fig. 3E and F) were consistent with the results presented in Fig. 3A and B. These findings suggested that ZBTB38 may promote the migration and invasive growth of bladder cancer cells, whereas it inhibited cell proliferation.

ZBTB38 accelerates the progression of epithelial-mesenchymal transition (EMT). The close association of EMT with cell migration and invasion is well documented (27). Advanced cancer often undergoes partial or full EMT; this process disrupts epithelial junction formation, and may contribute to invasion and metastasis. EMT is also a hallmark of malignant tumor progression, and the main cause of cancer-associated mortality. E-cadherin and ZO-1 are main epithelial markers, whereas vimentin and $\mathrm{N}$-cadherin are commonly used mesenchymal markers. $\beta$-catenin is a common transcription factor in the progression of EMT (27). Therefore, the present study detected the expression levels of E-cadherin, ZO-1, vimentin and $\beta$-catenin by western blotting. Alterations in the expression levels of EMT-associated proteins 
A

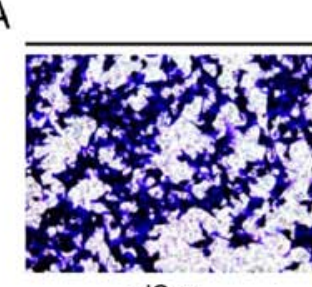

sicon
253J B-V

B

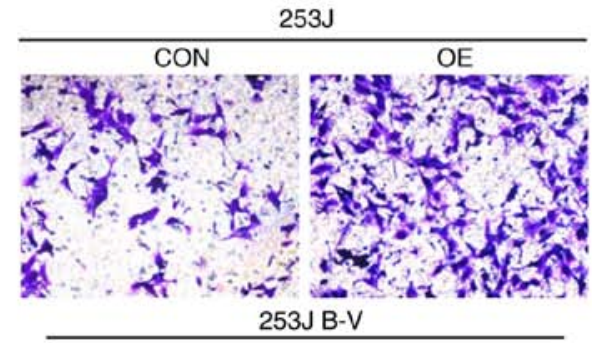

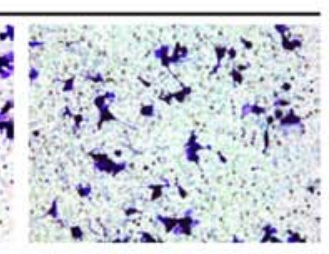

siZBTB38-2
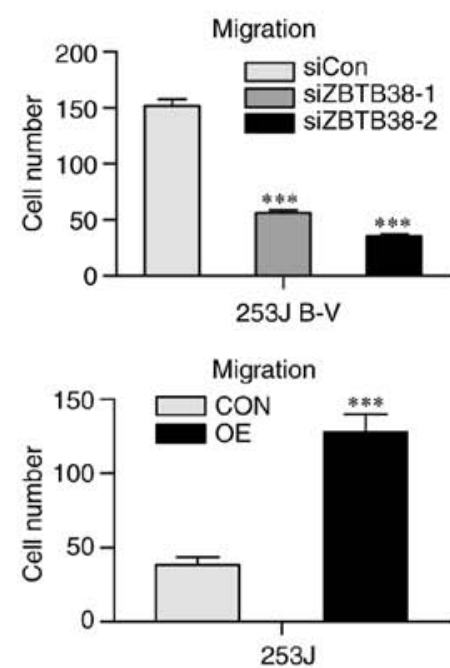

C
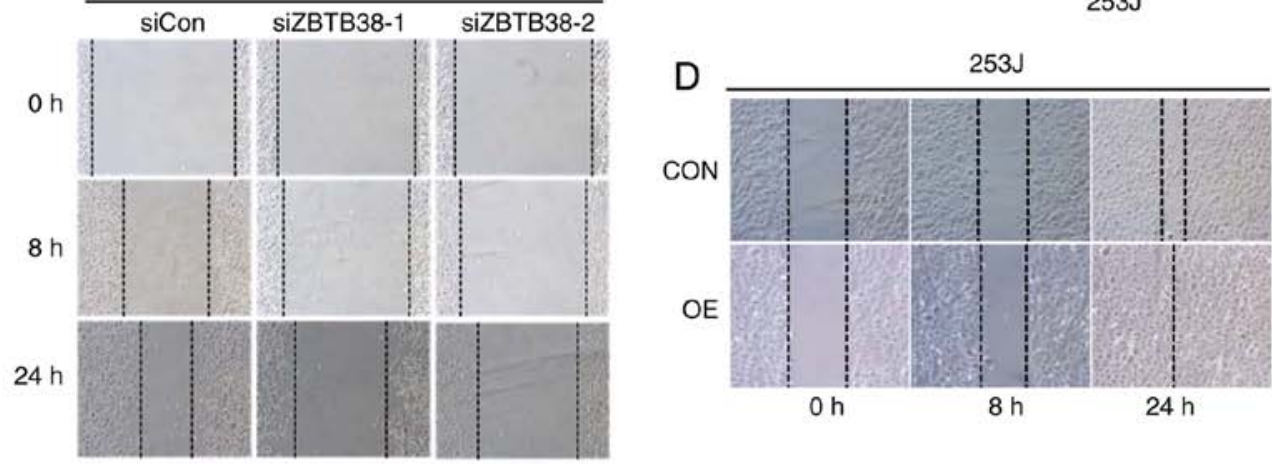

E

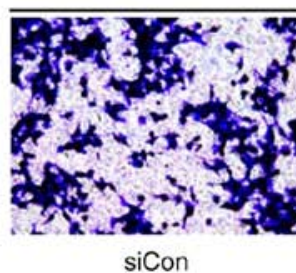

253J B-V

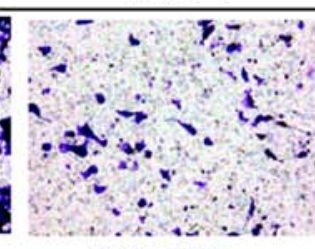

siZBTB38-1

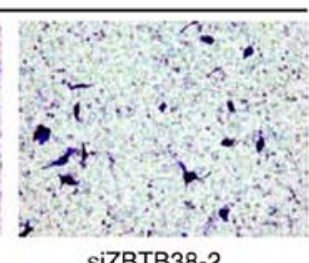

sizBTB38-2

F

253J
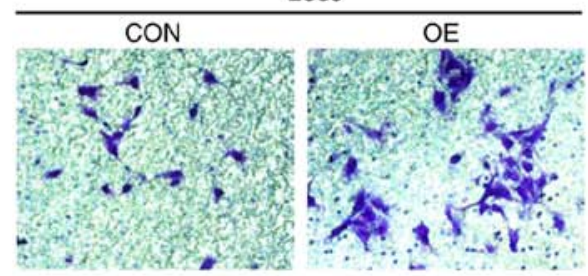
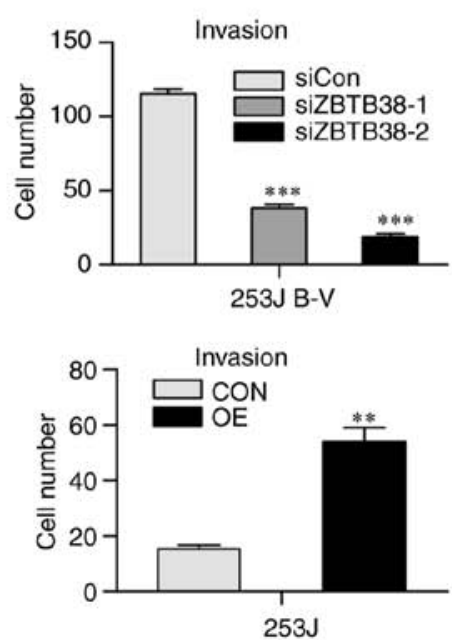

Figure 3. ZBTB38 promotes migration and invasive growth of bladder cancer cells. (A and B) Transwell migration assay of 253J B-V cells with ZBTB38 knockdown and 253J cells with ZBTB38 OE (magnification, x20). Each column represents the mean number of transmembrane cells in 3 randomly selected microscopic fields. (C and D) Wound-healing assay was used to detect migration of 253J B-V cells with ZBTB38 knockdown and of 253J cells with OE of ZBTB38 (magnification, x10). (E and F) Transwell invasion assay of 253J B-V cells with ZBTB38 knockdown and 253J cells with OE of ZBTB38 (magnification, $\mathrm{x} 20$ ). Each column represents the mean number of transmembrane cells in 3 randomly selected microscopic fields. siCon and CON were used as controls. Data are presented as the means \pm standard error of the mean. ${ }^{* *} \mathrm{P}<0.01,{ }^{* * * *} \mathrm{P}<0.001$ vs. siCon or CON cells. Con/CON, control; OE, overexpression; si $/$ siRNA, small interfering RNA; ZBTB28, zinc finger and BTB domain-containing 38.

were detected in ZBTB38 knockdown 253J B-V cells and in ZBTB38-overexpressing 253J cells. Loss of ZBTB38 in 253J $\mathrm{B}-\mathrm{V}$ cells enhanced the expression levels of E-cadherin and $\mathrm{ZO}-1$, whereas the expression levels of vimentin and $\beta$-catenin were decreased. Opposing results were observed in 253J cells overexpressing ZBTB38. Overexpression of ZBTB38 in $253 \mathrm{~J}$ cells decreased the expression levels of E-cadherin and $\mathrm{ZO}-1$, and increased the expression levels of vimentin. In addition, $\beta$-catenin expression was not significantly altered. Notably, ZBTB38 knockdown in 253J B-V cells induced a decrease in mesenchymal traits and an increase in epithelial features (Fig. 4A). Conversely, ZBTB38 overexpression in $253 \mathrm{~J}$ cells induced an increase in mesenchymal traits and a decrease in epithelial features (Fig. 4B). Similar results were obtained with regards to the mRNA expression levels of EMT components (Fig. 4C and D). 
A

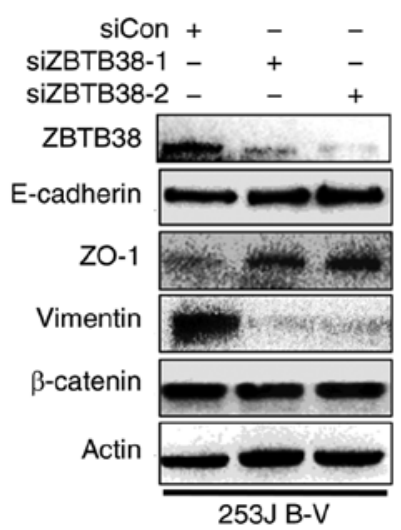

B

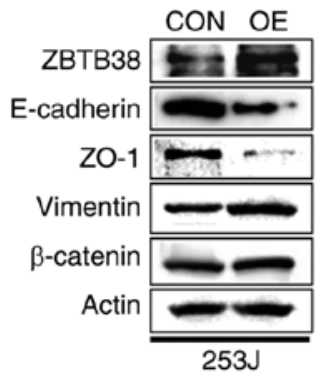

$\mathrm{C}$

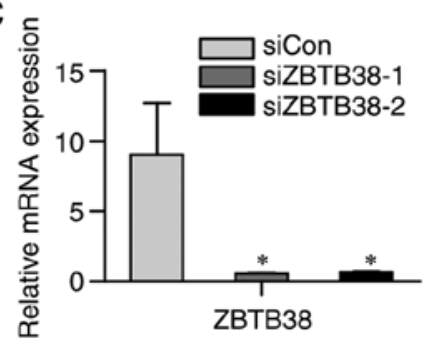

D

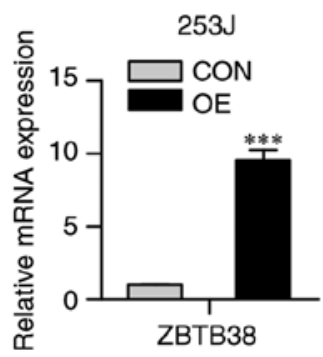

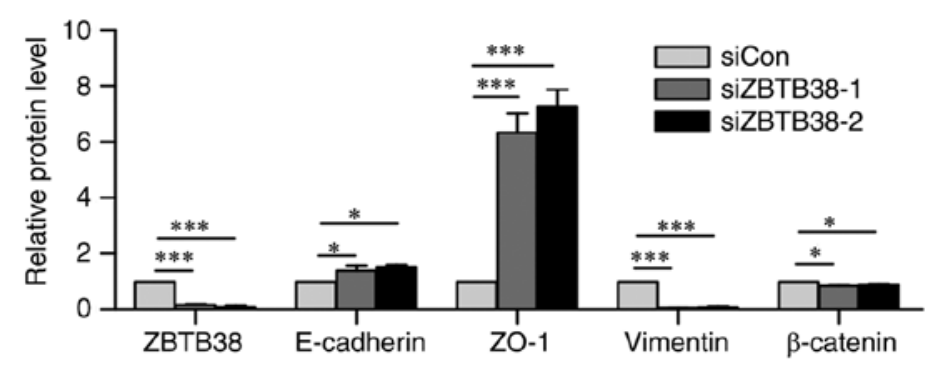
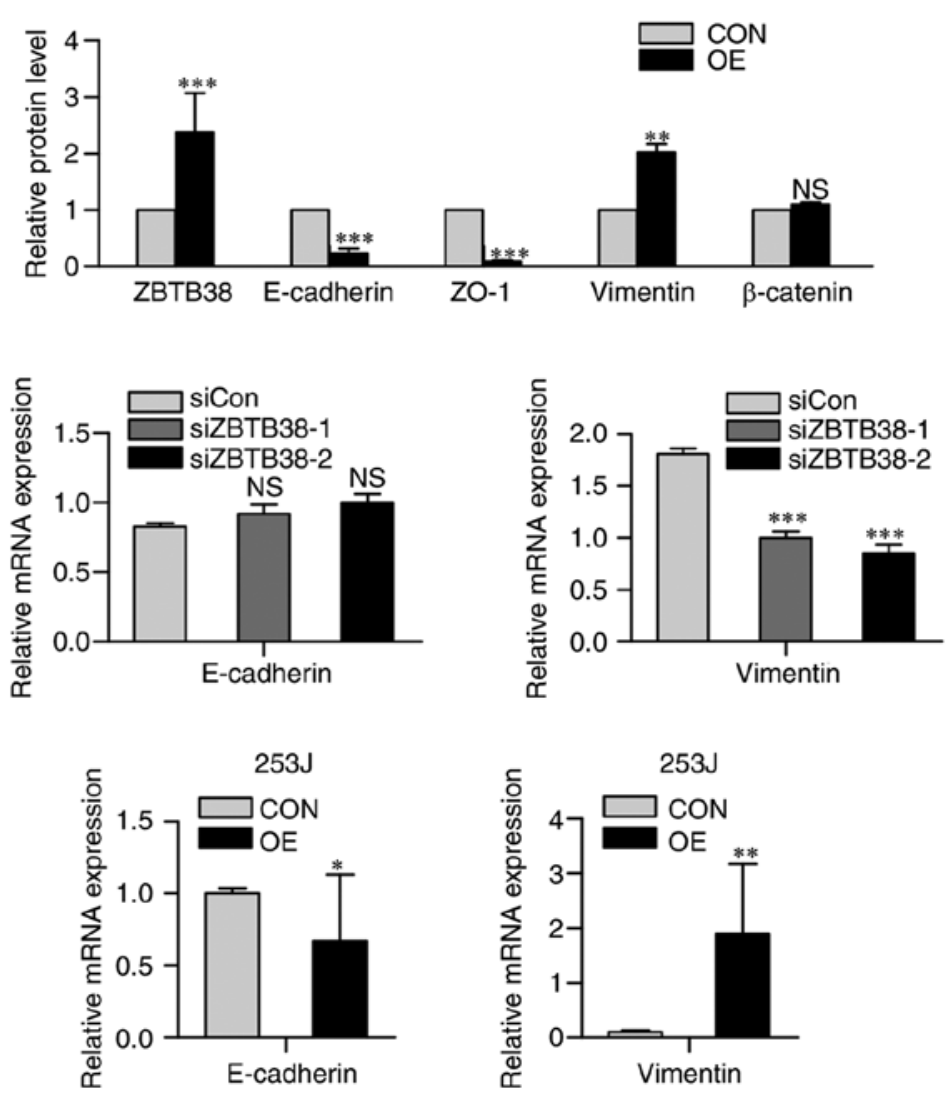

Figure 4. ZBTB38 accelerates EMT progression. (A) Western blot analysis of ZBTB38 and EMT markers in ZBTB38 knockdown 253J B-V cells. (B) Western blot analysis of ZBTB38 and EMT markers in ZBTB38-overexpressing 253J cells. (C and D) Results of reverse transcription-quantitative polymerase chain reaction analysis of the EMT markers E-cadherin and vimentin. The relative mRNA expression levels were normalized to GAPDH expression, which was analyzed in parallel as an internal control. siCon and CON were used as controls. Data are presented as the means \pm standard error of the mean. ${ }^{*}<0.05$, ${ }^{* *} \mathrm{P}<0.01,{ }^{* * *} \mathrm{P}<0.001$ vs. siCon or CON cells. NS, not significant; Con/CON, control; OE, overexpression; si/siRNA, small interfering RNA; ZBTB28, zinc finger and BTB domain-containing 38; ZO-1, zonula occludens 1.

ZBTB38 promotes Wht signaling pathway activity. ZBTB38 belongs to the Kaiso family, which all have similar domains and functions. It has previously been reported that Kaiso has a close connection with the Wnt signaling pathway (11). Therefore, it may be hypothesized that ZBTB38 is associated with Wnt; however, to the best of our knowledge, this has yet to be demonstrated. The present study detected alterations in downstream proteins of the Wnt signaling pathway, such as c-Myc and MET. Knockdown of ZBTB38 led to inhibition of the Wnt signaling pathway. Conversely, overexpression of ZBTB38 led to activation of the Wnt signaling pathway.
In order to further investigate this phenomenon, cells were treated with an activator or inhibitor of the Wnt signaling pathway, respectively (Fig. 5A and B). XAV939, which can specifically inhibit the $\mathrm{Wnt} / \beta$-catenin signaling pathway via inhibition of tankyrase $1 / 2$, was used as an inhibitor. SKL2001 is a novel activator of the Wnt/ $\beta$-catenin pathway, which can abolish the interaction between Axin/ $\beta$-catenin. Following treatment with SKL2001, the decreased expression levels of lymphoid enhancer binding factor 1 (LEF), c-Myc and MET in the knockdown group were significantly increased. In addition, TCF1 expression exhibited a similar trend; however, the 


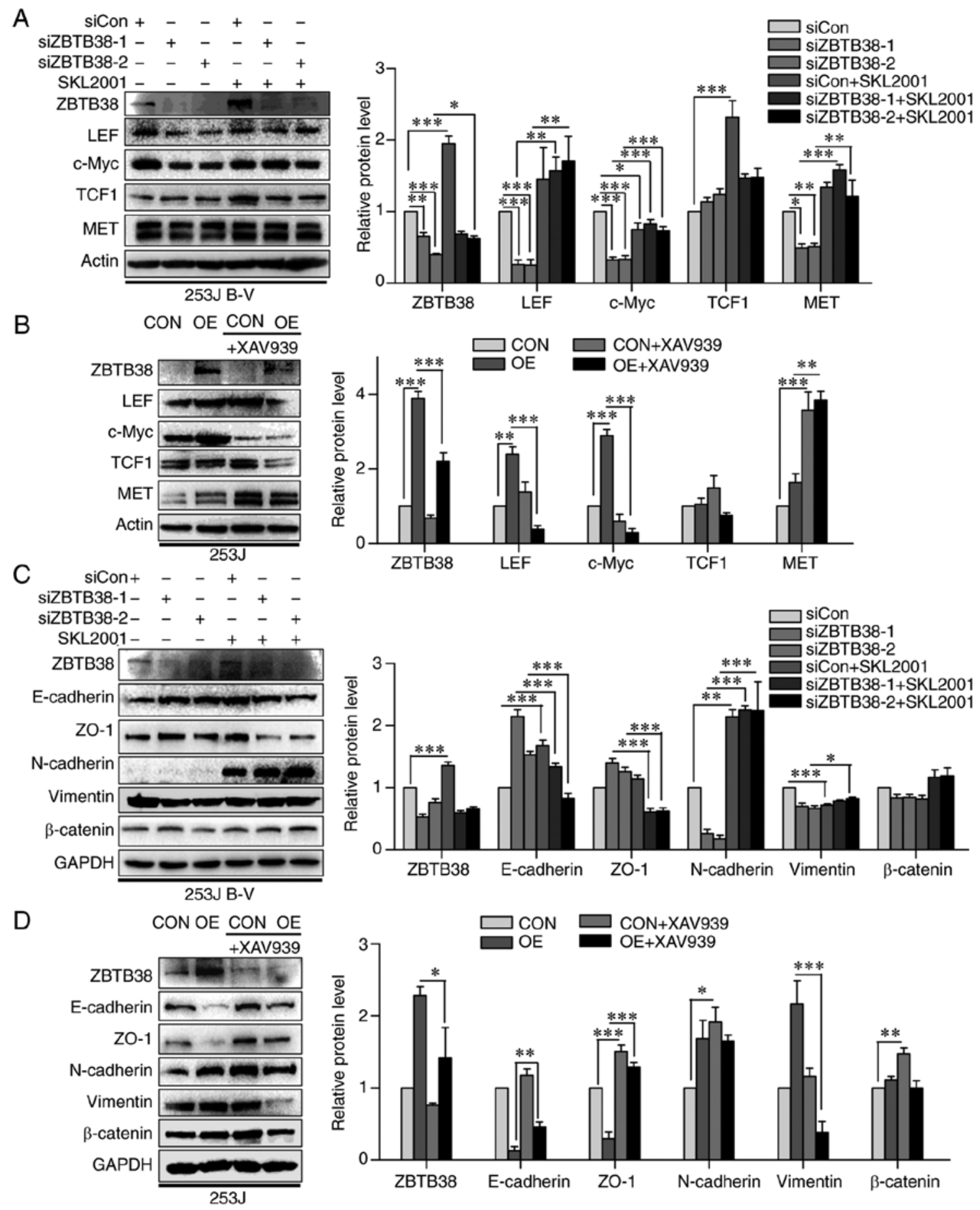

Figure 5. ZBTB38 promotes activity of the Wnt $/ \beta$-catenin signaling pathway. (A) Protein expression levels of Wnt/ $\beta$-catenin downstream proteins following ZBTB38 knockdown and SKL2001 treatment. (B) Protein expression levels of Wnt/ $\beta$-catenin downstream proteins following ZBTB38 overexpression and XAV939 treatment. (C) Expression levels of EMT markers following treatment of ZBTB38 knockdown 253J B-V cells with SKL2001. (D) Expression levels of EMT markers following treatment of ZBTB38-overexpressing 253J cells with XAV939. siCon and CON were used as controls. Data are presented as the means \pm standard error of the mean. ${ }^{*} \mathrm{P}<0.05,{ }^{* *} \mathrm{P}<0.01,{ }^{* * *} \mathrm{P}<0.001$ vs. siCon or $\mathrm{CON}$ cells. Con/CON, control; OE, overexpression; si/siRNA, small interfering RNA; ZBTB28, zinc finger and BTB domain-containing 38; ZO-1, zonula occludens 1.

findings were not statistically significant. As shown in Fig. 5A, treatment of ZBTB38 knockdown cells with SKL2001 led to an increase in the protein expression levels of downstream proteins of the $\mathrm{Wnt} / \beta$-catenin signaling pathway. Similarly, treatment of ZBTB38-overexpressing cells with XAV939 induced alterations in the expression levels of these downstream proteins (Fig. 5B). Following treatment with XAV939, the increased expression levels of LEF and c-Myc in the overexpression group were significantly decreased. The expression levels of TCF1 exhibited a similar trend; however, the findings were not statistically significant. Western blotting was conducted to examine whether EMT markers were affected by inhibition or activation of Wnt. Following treatment of the knockdown group with SKL2001, the increased expression levels of E-cadherin and ZO-1 were decreased, whereas the decreased expression levels of $\mathrm{N}$-cadherin and 
A
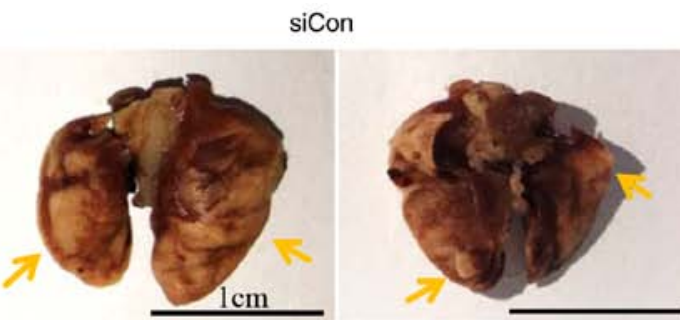

C
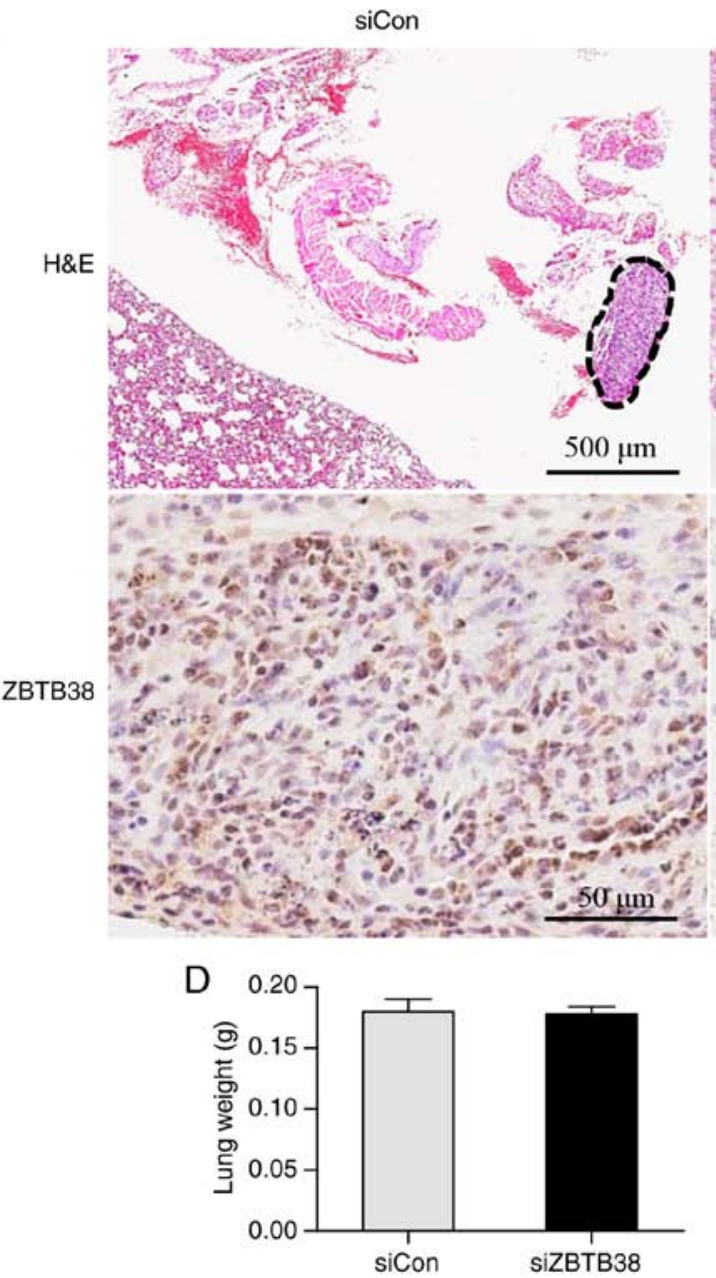

B
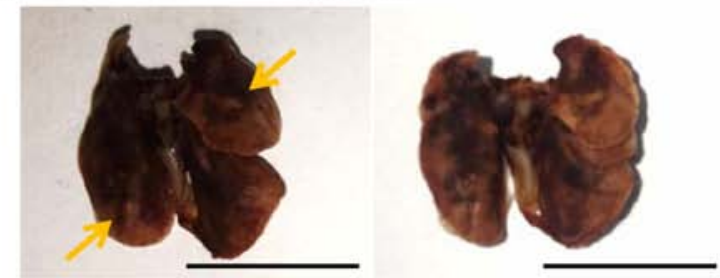

siZBTB38
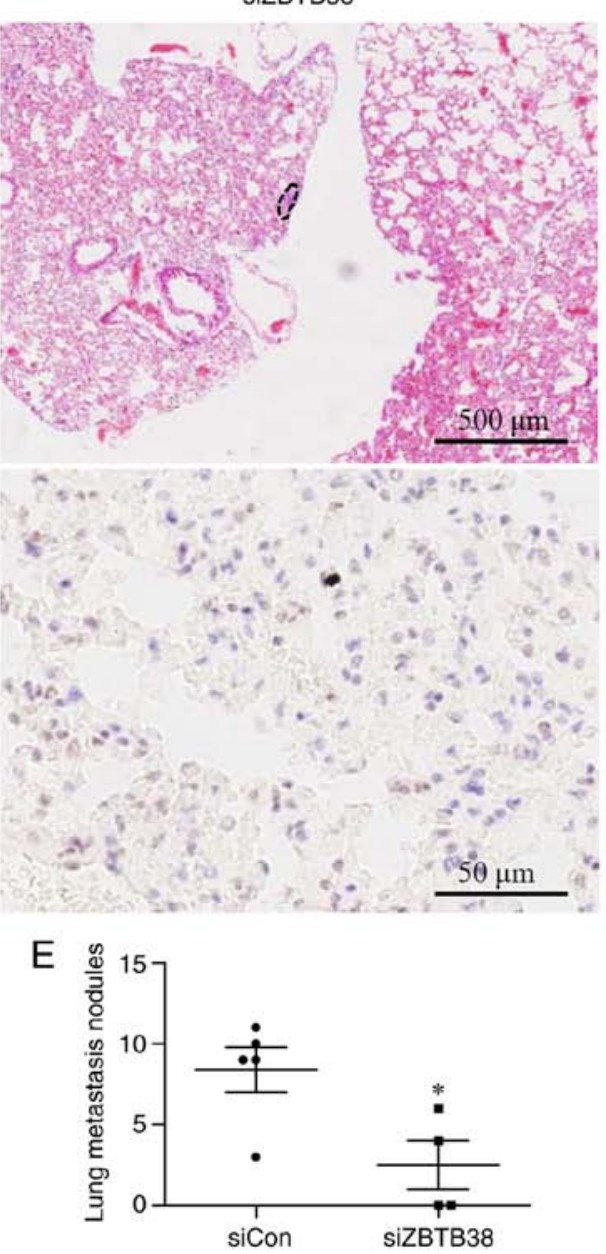

Figure 6. ZBTB38 promotes lung metastases in SCID mice. (A) Images of lungs possessing spontaneous metastases of siCon cells following caudal vein injection. (B) Images of lungs possessing spontaneous metastases of siZBTB38 253J B-V cells. (C) Hematoxylin and eosin staining and immunohistochemistry images. Metastatic lesions are circled with dashed lines. (D) Lung wet weight. (E) Scatter plot of lung metastasis. siCon was used as a control. Data are presented as the means \pm standard error of the mean. ${ }^{*} \mathrm{P}<0.05$ vs. siCon group. ZBTB28, zinc finger and BTB domain-containing 38 .

vimentin were increased. The expression levels of $\beta$-catenin were not markedly altered. As shown in Fig. 5C, epithelial features decreased and mesenchymal traits increased following treatment of ZBTB38 knockdown cells with SKL2001. Similarly, changes in EMT marker expression were observed following treatment of ZBTB38-overexpressing cells with XAV939 (Fig. 5D). Following treatment with XAV939, the decreased expression levels of E-cadherin and ZO-1 were increased, and the increased expression levels of vimentin were decreased. $\mathrm{N}$-cadherin expression exhibited a similar same trend; however, the findings were not statistically significant. There was also no significant alteration in $\beta$-catenin expression. These findings suggested that ZBTB38 may regulate activity of the Wnt/ $\beta$-catenin signaling pathway.
ZBTB38 promotes bladder cancer lung metastasis. Consistent with the database results, ZBTB38 expression exhibited a positive association with the metastatic capacity of bladder cancer cell lines. To elucidate the role of ZBTB38 in bladder cancer metastasis, $\sim 1 \times 10^{5}$ ZBTB38 knockdown $253 \mathrm{~J} \mathrm{B-V}$ cells and negative control cells were injected into the caudal veins of male SCID mice. After 4 weeks, all mice in the negative control group exhibited metastatic lesions in lungs (5/5), whereas only two mice in the experimental group developed metastatic lesions in the lungs caused by ZBTB38 knockdown cells (2/4). Lung metastatic nodules in the control group were much larger than in the ZBTB38-knockdown group (Fig. 6A-C). The wet lung weight in the ZBTB38 knockdown group was slightly lower than that in the negative control group; however, the difference 
was not statistically significant (Fig. 6D). Furthermore, the average number of metastatic nodules in the negative control group was $8.4 \pm 1.4$, whereas it was only $2.5 \pm 1.5$ in the ZBTB38 knockdown group; the number of lung metastatic nodules in the control group was significantly higher compared with in the ZBTB38 knockdown group (Fig. 6E). Collectively, these results suggested that ZBTB38 may promote bladder cancer lung metastasis.

\section{Discussion}

The present study demonstrated that ZBTB38 may promote the migration and invasion of bladder cancer cells via facilitating the Wnt/ $\beta$-catenin signaling pathway. Notably, to the best of our knowledge, the present study is the first to assess the role of ZBTB38 in bladder cancer. In our previous study (She et al, unpublished data), it was reported that the protein expression levels of ZBTB38 were higher in the highly aggressive bladder cancer cell line 253J B-V compared with in the less aggressive bladder cancer cell line 253J. Therefore, the present study investigated whether ZBTB38 promotes bladder cancer cell migration and invasion.

ZBTB38 is a Kaiso-like protein, which contains 10 $\mathrm{C}_{2} \mathrm{H}_{2}$-type zinc fingers domains and an N-terminal BTB/POZ domain (11). High protein expression levels of ZBTB38 have been reported to be associated with unfavorable DFS of patients. In the present study, transfection of $253 \mathrm{~J} \mathrm{B-V}$ cells with siRNA, in order to inhibit ZBTB38 expression, resulted in decreased migration and invasive growth compared with in the negative control cells. Subsequently, 253J cells overexpressing ZBTB38 exhibited an increase in the migration and invasive growth of cells compared with in the control cells. These results indicated that ZBTB38 expression may promote the migration and invasive growth of bladder cancer cells.

EMT is a vital step in cancer progression that enhances cell motility and invasion $(28,29)$. In ZBTB38 knockdown 253J B-V cells, the expression levels of E-cadherin were increased, whereas those of vimentin were decreased. Conversely, when ZBTB38 was overexpressed, the epithelial features decreased and the mesenchymal traits increased. Advanced cancer is often associated with metastasis and cancer cell death, and these cancer cells exhibit partial or full EMT (28). The present study revealed that patients with bladder cancer and increased ZBTB38 expression had a lower DFS. Therefore, overexpression of ZBTB38 may promote EMT, contribute to invasion and metastasis, and cause poor DFS of patients with bladder cancer. ZBTB38 belongs to the Kaiso family and loss of Kaiso has been reported to inhibit metastasis of triple-negative breast cancer $(30,31)$. Furthermore, Kaiso can promote migration and invasive growth of prostate cancer cells by regulating microRNA-31 (32). However, transfection of 253J B-V cells with siRNA, in order to decrease ZBTB38 expression, resulted in an increase in cell proliferation compared with in the negative control cells. Subsequently, 253J cells with ZBTB38 overexpression exhibited a decrease in proliferation compared with in the control cells. These results suggested that whether ZBTB38 functions as a potential oncogene or tumor suppressor remains unclear.

The Wnt/ $\beta$-catenin signaling pathway serves an important role in cell fate determination and may promote cancer progression (33-35). Kaiso, which is also named ZBTB33 and is a member of the ZBTB family, has been revealed to possess oncogenic activity; in addition, Kaiso can regulate TCF/LEF1-activity and formation of the $\beta$-catenin complex (36). ZBTB38 not only belongs to the ZBTB family, but is also termed a Kaiso-like protein, together with ZBTB4. Therefore, the present study aimed to investigate the association between ZBTB38 and the Wnt/ $\beta$-catenin signaling pathway. In the present study, inhibition of ZBTB38 expression suppressed the Wnt/ $\beta$-catenin pathway, whereas overexpression of ZBTB38 activated it. Following treatment with an activator or inhibitor of the $\mathrm{Wnt} / \beta$-catenin pathway, respectively, suppression and activation of the $\mathrm{Wnt} / \beta$-catenin pathway were reversed. In addition, the effects of ZBTB38 on EMT markers were also reversed upon treatment of the cells with the Wnt/ $\beta$-catenin pathway activator or inhibitor. These results indicated that ZBTB38 promotes the invasion and migration of bladder cancer cells by regulating the Wnt/ $\beta$-catenin pathway.

In conclusion, these findings suggested that ZBTB38 may be closely associated with bladder cancer. To the best of our knowledge, this is the first study to demonstrate that ZBTB38 may promote the migration and invasion of bladder cancer cells by affecting activity of the Wnt/ $\beta$-catenin signaling pathway. Collectively, these findings indicated that ZBTB38 may be a biomarker of poor prognosis for patients with bladder cancer. Based on the literature regarding Kaiso, it may be hypothesized that ZBTB38 affects the $\mathrm{Wnt} / \beta$-catenin pathway by regulating TCF/LEF1 activity. However, further studies are required to determine the definitive mechanism by which ZBTB38 affects the $\mathrm{Wnt} / \beta$-catenin pathway.

\section{Acknowledgements}

Not applicable.

\section{Funding}

The present study was supported by the National Natural Science Foundation of China (grant nos. 81272342, 81502620 and 81502413).

\section{Availability of data and materials}

The datasets used and/or analyzed during the present study are available from the corresponding author on reasonable request.

\section{Authors' contributions}

PL and JS initiated, conceived and designed the research. JJ participated in the design of the study, performed the experiments, and collected data. JL and YW participated in the MTT and invasion assays, and assisted with the drafting of the manuscript. MZ and LY assisted with the animal experiments. FS analyzed the data and performed the statistical analysis. All authors read and approved the final manuscript.

\section{Ethics approval and consent to participate}

The animal procedures were approved by the Institutional Animal Use and Care Committee of the Xi'an Jiaotong 
University (no. XJTULAC2018-505). The use of human bladder tissues was approved by the Ethical Committee on Human Research of the First Affiliated Hospital of Xi'an Jiaotong University (no. XJTU1AF2018LSK-101). Patients provided written informed consent for the use of their tissues.

\section{Patient consent for publication}

Not applicable.

\section{Competing interests}

The authors declare that they have no competing interests.

\section{References}

1. Siegel RL, Miller KD and Jemal A: Cancer Statistics, 2017. CA Cancer J Clin 67: 7-30, 2017.

2. Massari F, Santoni M, di Nunno V, Cheng L, Lopez-Beltran A Cimadamore A, Gasparrini S, Scarpelli M, Battelli N and Montironi R: Adjuvant and neoadjuvant approaches for urothelial cancer: Updated indications and controversies. Cancer Treat Rev 68: 80-85, 2018.

3. Mertens LS, Neuzillet Y, Horenblas S and van Rhijn BW: Landmarks in non-muscle-invasive bladder cancer. Nat Rev Urol 11: 476-480, 2014.

4. van Rhijn BW, Vis AN, van der Kwast TH, Kirkels WJ Radvanyi F, Ooms EC, Chopin DK, Boevé ER, Jöbsis AC and Zwarthoff EC: Molecular grading of urothelial cell carcinoma with fibroblast growth factor receptor 3 and MIB-1 is superior to pathologic grade for the prediction of clinical outcome. J Clin Oncol 21: 1912-1921, 2003.

5. Zhang X and Zhang Y: Bladder cancer and genetic mutations. Cell Biochem Biophys 73: 65-69, 2015.

6. Knowles MA and Hurst CD: Molecular biology of bladder cancer: New insights into pathogenesis and clinical diversity. Nature Rev Cancer 15: 25-41, 2015.

7. Knowles MA: Molecular subtypes of bladder cancer: Jekyll and Hyde or chalk and cheese? Carcinogenesis 27: 361-373, 2006.

8. Mukherjee N, Houston TJ, Cardenas E and Ghosh R: To be an ally or an adversary in bladder cancer: The NF-kappaB story has not unfolded. Carcinogenesis 36: 299-306, 2015.

9. Kim J, Akbani R, Creighton CJ, Lerner SP, Weinstein JN, Getz G and Kwiatkowski DJ: Invasive bladder cancer: Genomic insights and therapeutic promise. Clin Cancer Res 21: 4514-4524, 2015.

10. Houede N and Pourquier P: Targeting the genetic alterations of the PI3K-AKT-mTOR pathway: Its potential use in the treatment of bladder cancers. Pharmacol Ther 145: 1-18, 2015.

11. Filion GJ, Zhenilo S, Salozhin S, Yamada D, Prokhortchouk E and Defossez PA: A family of human zinc finger proteins that bind methylated DNA and repress transcription. Mol Cell Biol 26: 169-181, 2006.

12. Kiefer H, Chatail-Hermitte F, Ravassard P, Bayard E, Brunet I and Mallet J: ZENON, a novel POZ Kruppel-like DNA binding protein associated with differentiation and/or survival of late postmitotic neurons. Mol Cell Biol 25: 1713-1729, 2005.

13. Miotto B, Chibi M, Xie P, Koundrioukoff S, Moolman-Smook H, Pugh D, Debatisse M, He F, Zhang L and Defossez PA: The RBBP6/ZBTB38/MCM10 axis regulates DNA replication and common fragile site stability. Cell Rep 7: 575-587, 2014.

14. Kote-Jarai Z, Olama AA, Giles GG, Severi G, Schleutker J, Weischer M, Campa D, Riboli E, Key T, Gronberg H, et al: Seven prostate cancer susceptibility loci identified by a multi-stage genome-wide association study. Nat Genet 43: 785-791, 2011.

15. Miotto B, Marchal C, Adelmant, Guinot N, Xie P, Marto JA, Zhang L and Defossez PA: Stabilization of the methyl-CpG binding protein ZBTB38 by the deubiquitinase USP9X limits the occurrence and toxicity of oxidative stress in human cells. Nucleic Acids Res 46: 4392-4404, 2018.
16. Sun Z, Cao Y, Hu G, Zhao J, Chen M, Wang S, Ye Z, Chen H, Wang W and Wang Y: Jinfu'an decoction inhibits invasion and metastasis in human lung cancer cells (H1650) via p120ctn-mediated induction and Kaiso. Med Sci Monit 24: 2878-2886, 2018.

17. Jones J, Wang H, Zhou J, Hardy S, Turner T, Austin D, He Q, Wells A, Grizzle WE and Yates C: Nuclear Kaiso indicates aggressive prostate cancers and promotes migration and invasiveness of prostate cancer cells. Am J Pathol 181: 1836-1846, 2012.

18. Kourtidis A, Lu R, Pence LJ and Anastasiadis PZ: A central role for cadherin signaling in cancer. Exp cell Res 358: 78-85, 2017.

19. Kourtidis A, Ngok SP and Anastasiadis PZ: P120 catenin: An essential regulator of cadherin stability, adhesion-induced signaling, and cancer progression. Prog Mol Biol Transl Sci 116: 409-432, 2013

20. Iioka H, Doerner SK and Tamai K: Kaiso is a bimodal modulator for Wnt/beta-catenin signaling. FEBS Lett 583: 627-632, 2009.

21. Clevers H: Wnt/beta-catenin signaling in development and disease. Cell 127: 469-480, 2006.

22. Logan CY and Nusse R: The Wnt signaling pathway in development and disease. Annu Rev Cell Dev Biol 20: 781-810, 2004.

23. Pierzynski JA, Hildebrandt MA, Kamat AM, Lin J, Ye Y, Dinney CP and Wu X: Genetic variants in the Wnt/beta-catenin signaling pathway as indicators of bladder cancer risk. J Urol 194: 1771-1776, 2015.

24. Colin P, Fishbeck R, Singh RK, Eve B, Pathak S, Brown N, Xie B, Fan D, Bucana CD and Fidler IJ: Isolation and characterization of metastatic variants from human transitional cell carcinoma passaged by orthotopic implantation in athymic nude mice. J Urol 154: 1532-1538, 1995.

25. Livak KJ and Schmittgen TD: Analysis of relative gene expression data using real-time quantitative PCR and the $2^{-\Delta \Delta C_{\mathrm{T}}}$ method. Methods 25: 402-408, 2001.

26. Wallace J: Humane endpoints and cancer research. ILAR J 41: 87-93, 2000.

27. Tang Z, Li C, Kang B, Gao G, Li C and Zhang Z: GEPIA: A web server for cancer and normal gene expression profiling and interactive analyses. Nucleic Acids Res 45: W98-W102, 2017.

28. Thiery JP and Sleeman JP: Complex networks orchestrate epithelial-mesenchymal transitions. Nat Rev Mol Cell Biol 7: 131-142, 2006.

29. Gilles C, Polette M, Mestdagt M, Nawrocki-Raby B, Ruggeri P, Birembaut $\mathrm{P}$ and Foidart JM: Transactivation of vimentin by beta-catenin in human breast cancer cells. Cancer Res 63: 2658-2664, 2003.

30. Kwiecien JM, Bassey-Archibong BI, Dabrowski W, Rayner LG, Lucas AR and Daniel JM: Loss of Kaiso expression in breast cancer cells prevents intra-vascular invasion in the lung and secondary metastasis. PLoS One 12: e0183883, 2017.

31. Bassey-Archibong BI, Kwiecien JM, Milosavljevic SB, Hallett RM, Rayner LG, Erb MJ, Crawford-Brown CJ, Stephenson KB, Bédard PA, Hassell JA, et al: Kaiso depletion attenuates transforming growth factor-beta signaling and metastatic activity of triple-negative breast cancer cells. Oncogenesis 5: e208, 2016.

32. Wang H, Liu W, Black S, Turner O, Daniel JM, Dean-Colomb W, He QP, Davis M and Yates C: Kaiso, a transcriptional repressor, promotes cell migration and invasion of prostate cancer cells through regulation of miR-31 expression. Oncotarget 7: 5677-5689, 2016.

33. Takebe N, Miele L, Harris PJ, Jeong W, Bando H, Kahn M, Yang SX and Ivy SP: Targeting Notch, Hedgehog, and Wnt pathways in cancer stem cells: Clinical update. Nat Rev Clin Oncol 12: 445-464, 2015

34. Xi Y and Chen Y: Wnt signaling pathway: Implications for therapy in lung cancer and bone metastasis. Cancer Lett 353 . $8-16,2014$.

35. Anastas JN and Moon RT: WNT signalling pathways as therapeutic targets in cancer. Nat Rev Cancer 13: 11-26, 2013.

36. Prokhortchouk A, Sansom O, Selfridge J, Caballero IM, Salozhin S, Aithozhina D, Cerchietti L, Meng FG, Augenlicht LH, Mariadason JM, et al: Kaiso-deficient mice show resistance to intestinal cancer. Mol Cell Biol 26: 199-208, 2006. 